\title{
PRÁTICAS EDUCATIVAS EM SAÚDE NA FORMAÇÃO DE ACADÊMICOS DE ENFERMAGEM
}

Francisco Gilberto Fernandes Pereira', Joselany Áfio Caetano², Juliana Faheina Moreira³, Márcia Barroso Camilo de Ataíde²

'Enfermeiro. Mestrando em Enfermagem. Docente do Centro Universitário Estácio do Ceará. Fortaleza-CE-Brasil ${ }^{2}$ Enfermeira. Doutora em Enfermagem. Docente da Universidade Federal do Ceará. Fortaleza-CE-Brasil ${ }^{3}$ Enfermeira. Especialista em Gestão e Auditoria de Serviços de Saúde. Hospital Antonio Prudente. Fortaleza-CE-Brasil

RESUMO: Objetivou-se compreender a importância das práticas educativas em saúde na formação de acadêmicos de enfermagem, por meio de um estudo descritivo qualitativo, realizado entre os meses de setembro a outubro de 2014 com cinquenta estudantes de enfermagem. As informações foram coletadas por entrevista semiestruturada, os depoimentos organizados e analisados conforme o Discurso do Sujeito Coletivo. Foram respeitadas as normas éticas por meio do parecer 889.504. Emergiram os três discursos-síntese, ancorados nas seguintes ideias centrais: conceito de Educação em Saúde; importância das práticas educativas na formação acadêmica; e, dificuldades ao executar atividades educativas. Nota-se que há convergências entre o modelo biomédico e a execução das atividades educativas, no entanto é evidenciada como importante ferramenta de construção profissional. Por fim, conclui-se que a Educação em Saúde ocupa posição de destaque na formação de acadêmicos de enfermagem, no entanto, sendo necessário rediscutir seu conceito.

DESCRITORES: Educação em saúde; Estudantes de enfermagem; Promoção da saúde.

\section{HEALTH EDUCATION PRACTICES IN THE TRAINING OF NURSING UNDERGRADUATES}

\begin{abstract}
The aim of this study was to understand the importance of health education practices in the training of nursing undergraduate students, through a qualitative descriptive study, conducted between September and October 2014 with fifty nursing undergraduates. Data were collected by means of semi-structured interviews; the statements were organized and analyzed according to the Collective Subject Discourse. Ethical standards were applied by means of opinion 889.504. Three synthetic discourses emerged, anchored on the following core ideas: concept of health education; importance of educational practices in academic education; and, difficulties in performing educational activities. It can be noted that there are similarities between the biomedical model and the implementation of educational activities; however, these are evidenced as an important professional building tool. Health education occupies a prominent position in the training of nursing students; however, it is necessary to rediscuss its concept.
\end{abstract}

DESCRIPTORS: Health education; Nursing students; Health promotion.

\section{PRÁCTICAS EDUCATIVAS EN SALUD EN LA FORMACIÓN DE ACADÉMICOS DE ENFERMERÍA}

RESUMEN: El objetivo de la investigación fue comprender la importancia de las prácticas educativas en salud para la formación de académicos de enfermería, por medio de un estudio descriptivo cualitativo, realizado entre los meses de septiembre y octubre de 2014 con cincuenta estudiantes de enfermería. Las informaciones fueron obtenidas por entrevista semiestructurada; los testimonios, organizados y analizados de acuerdo con el Discurso del Sujeto Colectivo. Fueron respetadas las normas éticas por medio del parecer 889.504. Surgieron tres discursos síntesis, fundamentados en las siguientes ideas centrales: concepto de Educación en Salud; importancia de las prácticas educativas en la formación académica; y dificultades al ejecutar actividades educativas. Se percibe que hay convergencias entre el modelo biomédico y la ejecución de las actividades educativas, pero estas son evidenciadas como importantes herramientas de construcción profesional. Así, se concluye que la Educación en Salud es esencial en la formación de académicos de enfermería, siendo necesario, sin embargo, rediscutir su concepto.

DESCRIPTORES: Educación en salud; Estudiantes de enfermería; Promoción de la salud. 


\section{INTRODUÇÃO}

Educação em Saúde é um processo educativo dinâmico de construção de conhecimentos em saúde que visa à apropriação temática pela população, tornando-se um conjunto de práticas que contribui para aumentar a autonomia das pessoas no seu cuidado. Busca fortalecer um modelo de atenção em saúde que valorize as necessidades dos indivíduos, bem como potencializar o exercício do controle social sobre as políticas e os serviços de saúde para que estes respondam às necessidades da população(1) ${ }^{(1)}$ Assim, a Educação em Saúde tem como objetivo promover a inclusão social e a promoção da autonomia das populações na participação em saúde.

Sendo objetivos primordiais da prestação de cuidados de enfermagem promover a saúde e a qualidade de vida das pessoas e providenciar um ambiente humano e seguro, a educação em enfermagem deverá ter em conta esse direcionamento e preparar os estudantes para esse tipo de cuidados $^{(2)}$. Essa preparação deverá envolver uma base teórica adequada, mas também dar atenção às atitudes, aos valores e às competências para que os futuros profissionais, chegados ao mercado de trabalho, possam prestar cuidados de qualidade e serem verdadeiros promotores da saúde da população e não concebam a Educação em Saúde apenas como um orientar e ensinar a prevenir doenças ${ }^{(3)}$.

Neste sentido, as Escolas de Enfermagem de nível superior têm permeado seus currículos com grande ênfase aos ensinamentos da Educação em Saúde, bem como têm fundamentado suas práticas colocando esse tema de modo transversal em todas as disciplinas assistenciais. No entanto, não foram encontrados estudos que demonstrassem a situação desse fenômeno no ensino técnico-profissionalizante.

O estudo é pertinente, pois salienta a consciencialização que os alunos dos cursos nele incluídos, em escolas de enfermagem no Brasil, têm sobre os valores em Educação em Saúde, a necessidade de trabalhar esses conteúdos atitudinais e de apontar os valores metodológicos e filosóficos aos quais deve ser dada maior atenção em cada um dos cursos. A formação em enfermagem, especificamente, não pode ser alheia à questão dos valores em Educação em Saúde.
Assim, temos que ter em mente que os programas de Educação em Saúde não devem se limitar a iniciativas que visem informar a população sobre os problemas de saúde. Devem ir além do campo da informação, considerando os valores, costumes e modelos sociais que levam a condutas e práticas educativas libertadoras, em que profissional e usuário são vistos como sujeitos, com papéis significativos, capazes de promover mudanças na realidade enfrentada por ambos e no modelo de saúde atual(4).

Portanto, o processo de formação pode instrumentalizar os egressos com competência técnica e política, o que permitiria ao enfermeiro, assumir postura condizente e consciente com o seu saber-fazer e de acordo com as reais necessidades da clientela ${ }^{(5)}$. Foi objetivo deste estudo compreender a importância das práticas de Educação em Saúde na formação de acadêmicos de enfermagem.

\section{METODOLOGIA}

O estudo é do tipo descritivo exploratório com abordagem predominantemente qualitativa dada as características das variáveis. A pesquisa se desenvolveu entre os meses de janeiro e fevereiro de 2015 em uma Instituição privada de Ensino Superior (IES) com acadêmicos do curso de enfermagem. Nesta instituição o bacharelado em enfermagem tem duração de cinco anos com uma grade curricular composta de carga horária teórica em sala de aula durante todo o curso, e prática em laboratórios de simulação e na rede assistencial do município de Fortaleza (postos de saúde, clínicas e hospitais), estado do Ceará, a partir do quarto período.

A população pesquisada compreende um grupo de 200 alunos os quais estão vivenciando, por ocasião dos seus respectivos períodos acadêmicos, as práticas de Educação em Saúde. Desta, foram selecionados para sujeitos informantes aproximadamente 50 pessoas de modo que se obteve uma maior qualidade das respostas apresentas para auxiliar na análise e discussão dos resultados, mediante o critério de saturação das respostas. Os critérios de inclusão foram: estudantes do $4^{\circ}$ ao $10^{\circ}$ período do curso de graduação em Enfermagem e que já tivessem realizado ou vivenciado pelo 
menos uma atividade educativa em saúde em unidades assistenciais nos estágios curriculares. Foram excluídos aqueles que ainda não haviam participado da execução de ES.

As informações foram coletadas mediante aplicação de uma entrevista semiestruturada, realizadas individualmente, em sala reservada, garantindo-lhes o anonimato pelas informações prestadas e oferecendo-Ihes liberdade para explorar suas experiências. A entrevista conteve questões relacionadas à vivência, importância e fragilidades sentidas por esses alunos durante as atividades educativas nos serviços de saúde junto à clientela.

A organização dos depoimentos se deu por meio da técnica do Discurso do Sujeito ColetivoDSC ${ }^{(6)}$ que é uma proposta de organização e tabulação de dados qualitativos de natureza verbal, obtidos de depoimentos. Tendo como fundamento a teoria da Representação Social e seus pressupostos sociológicos, a proposta consiste basicamente em analisar o material verbal coletado, extraído de cada um dos depoimentos. O Discurso do Sujeito Coletivo é uma modalidade de apresentação de resultados de pesquisas qualitativas, que tem depoimentos como matéria prima, sob a forma de um ou vários discursos-síntese escritos na primeira pessoa do singular, expediente que visa expressar o pensamento de uma coletividade, como se esta coletividade fosse o emissor de um discurso.

Esta técnica consiste em selecionar, de cada resposta individual a uma questão, as ExpressõesChave, que são trechos mais significativos destas respostas. A essas Expressões Chaves correspondem Ideias Centrais (IC) que são a síntese do conteúdo discursivo manifestado nas Expressões Chave. Com o material das Expressões Chave das Ideias Centrais constroem-se discursossíntese, na primeira pessoa do singular, que são os DSCs, nos quais o pensamento de um grupo ou coletividade aparece como se fosse um discurso individual $^{(6)}$.

Assim, neste estudo, foram construídos três DSC, a partir das seguintes IC: IC - A: Conceito de Educação em Saúde; IC - B: Importância das práticas educativas na formação acadêmica; IC C: Dificuldades ao executar atividades educativas.

Foram respeitados todos os aspectos bioéticos de acordo com a Resolução 466/12(7) do Ministério da Saúde, mediante autorização ética com o parecer 889.504, emitido pelo Comitê de
Ética em Pesquisa do Centro Universitário Estácio do Ceará.

\section{RESULTADOS}

Mediante a organização dos depoimentos extraíram-se as seguintes Expressões-Chave: Educação em Saúde; intervenção; palestra; paciente; mudança de comportamento; saúde; doença; trabalho em equipe; e, atenção básica. A partir daí, três DSC foram organizados em função das respostas suscitadas da aplicação das entrevistas semiestruturadas.

No primeiro, em função da IC - A extraiu-se o conceito ora internalizado pelos acadêmicos de enfermagem acerca do tema Educação em Saúde, no qual se percebeu que ainda há resquícios do modelo biomédico na construção conceitual, dando-lhe um caráter eminentemente preventivo. Por outro lado, ressalta-se que a incorporação das diretrizes fundamentais do sistema de saúde contemporâneo também estão imbricadas nos depoimentos, como por exemplo: multidisciplinaridade, participação social, universalidade e regionalidade.

\section{IC A: Conceito de Educação em Saúde}

Educação em Saúde é um tipo de intervenção que os profissionais de saúde podem utilizar para esclarecer a população sobre meios de prevenir doenças, como também direcionar para o acesso aos serviços de saúde. Ela pode ser feita através de palestras, oficinas, rodas de conversas, enfim, dependendo do tipo de assunto que vai ser abordado e do público alvo, as estratégias podem ir mudando. Talvez ela ajude a mudar o comportamento das pessoas sobre determinados conceitos ou pré-conceitos. (DSC - A)

No segundo DSC há aspectos relativos aos que foram suscitados em relação à IC B, que corresponde ao grau de importância que os estudantes de enfermagem atribuem a execução das atividades de educação sem saúde para sua formação profissional e curricular. É perceptível que os acadêmicos compreendem esse momento educativo com um elevado grau de importância no contexto de promoção de saúde, pois se esforçam ao máximo para clarificar 
as informações fornecidas nas sessões educativas.

Também, é possível extrair do DSC - B que o ato de preparar uma atividade educativa, desperta o estudante para aumentar sua base de conhecimentos teóricos sobre os mais variados assuntos, demonstrando assim, que no processo educativo há um benefício duplo, tanto para o cliente, quanto para o educador-aluno.

\section{IC B: Importância das práticas educativas na formação acadêmica}

Sim, são importantes porque a gente tem a possibilidade de conviver com todo tipo de gente, desde aquelas mais esclarecidas, àquelas que você tem que 'se virar nos 30' para poder conseguir colocar as informações de forma clara. Acho também que é importante porque toda vez que a gente vai fazer uma palestra a gente estuda, se esforça para aprender mais sobre o tema, e acabam tanto a gente quanto os pacientes ganhando. Uma coisa boa, é que a supervisão dos professores dá uma segurança maior, aí a gente acaba se sentindo mais confiante em passar as informações. '

Quanto às dificuldades apresentadas durante a execução de sessões educativas, foi reportado no DSC - C que há fatores que vão desde a infraestrutura precária dos serviços a quantidade de tempo dispensada para o planejamento e avaliação da eficácia das atividades.

Outro aspecto importante, é que o estudante sente a necessidade de ampliar os cenários de experimentação das atividades educativas, sugerindo, por exemplo, o ambiente hospitalar, o qual em virtude de possuir uma maior herança do modelo biomédico, ainda não é tão fértil para esse tipo de intervenção.

\section{IC C: Dificuldades ao executar atividades educativas}

A parte mais complicada de se fazer Educação em Saúde é que nem sempre você tem domínio de certos assuntos, por mais que você estude. $E$, também, como a gente passa pouco tempo nos campos de prática, não tem como a gente saber se o que foi ensinado por nós será incorporado pelo paciente, porque a gente sabe que é muito difícil mudar o comportamento das pessoas, principalmente aquelas mais idosas. Outra coisa que dificulta, é que na maioria das vezes não tem um ambiente acolhedor para fazer as oficinas, por exemplo, aí as pessoas ficam inquietas, por causa do desconforto, e também isso limita muito a gente de criar coisas diferentes para facilitar a transmissão das informações. Tive a oportunidade de fazer Educação em Saúde, mas poderia ter tido mais, por exemplo, no hospital. É muito comum a gente fazer no posto de saúde, em centros comunitários, em escolas, mas no hospital é mais difícil. (DSC - C)

\section{DISCUSSÃO}

Consoante se evidencia neste estudo, os acadêmicos conceituaram a Educação em Saúde como uma forma de 'ensinar os pacientes a prevenir doenças', o que se traduz numa visão reducionista da capacidade ampla que tal atividade possui. Explica-se essa concepção, provavelmente, por ainda haver uma herança do modelo cartesiano nos modelos curriculares e na cultura popular, desenvolvendo um enfoque mecanicista que apresenta a ideia de que educar tem a finalidade inseparável ao ato de prevenir. Este é de fato um paradigma que tende a reduzir as práticas educativas em saúde a atividades preventivas, de cunho meramente informativo e coercitivo ${ }^{(8)}$.

A Educação em Saúde deve ser pautada como um instrumento de intervenção na realidade, onde haja a priorização de compartilhamento de saberes, visando a criação de um ambiente de troca, propício para a aquisição de comportamentos saudáveis ou de minimização de $\operatorname{riscos}^{(9-10)}$. Neste estudo, percebeu-se que os acadêmicos buscam, ainda de que de forma tímida, incorporar a necessidade do trabalho educativo aos saberes da clientela, e colocá-la na posição de sujeito ativo no processo de construção e consolidação do conhecimento em saúde.

O sujeito ativo nesse processo fortalece o vínculo com as equipes de saúde, favorece a organização popular permitindo a inclusão de novos atores no campo da saúde, ampliando assim o diálogo que considere o saber popular nas práticas de Educação em Saúde ${ }^{(11)}$.

Desse modo, há de se incorporar o ensino 
cujas práticas de Educação em Saúde sejam voltadas à promoção da saúde das populações sem a égide do modelo tecnicista, indo além da transmissão de conhecimento, estabelecendo vínculo afetivo com os sujeitos envolvidos, reduzindo o distanciamento entre as instituições de saúde e a população.

Nota-se que, atualmente, são grandes os esforços das Instituições de Ensino Superior em atender as diretrizes do Ministério da Educação no tocante à formação de profissionais mais comprometidos com a humanização do atendimento e da relação com o cliente. Neste sentido, a inserção de atividades de Educação em Saúde na formação de estudantes da área de saúde é uma importante ferramenta de construção do futuro profissional, pois, vista como uma prática social pode ser pensada como um modo de promover a reflexão e a consciência crítica das pessoas sobre sua situação de vida ${ }^{(10)}$.

Entretanto, ainda é necessário o desenvolvimento de políticas mais intensivas de formação de profissionais de saúde que considerem a educação popular como método nas suas formações ${ }^{(11)}$. As concepções sobre os valores em práticas educativas em saúde são distintas entre os cursos da área da saúde e os da área das ciências sociais e humanas. Nos cursos de enfermagem ocorre maior evolução dos valores, nos quais se enfatizam os valores social, holístico, autonomia e democracia ${ }^{(12)}$.

As inferências apresentadas com essa pesquisa corroboram contundentemente a outra avaliação de práticas educativas em saúde no ensino de enfermagem, que ao verificar as dimensões do processo educativo, concepção crítica de educação e interdisciplinaridade, concluiu que o ensino desenvolvido permanece majoritariamente vinculado ao modelo biomédico preventivo, e que as concepções de educação crítica e as práticas educativas 'populares' são escassas, devido à deficitária formação política dos docentes e, mais amplamente, como consequência do enfrentamento de contexto acadêmico de implementação do ideário neoliberal ${ }^{(13)}$.

Pesquisa realizada na realidade brasileira descreve que embora os profissionais tenham correta sedimentação acerca do conceito de Educação em Saúde, há um hiato entre a teoria e prática, uma vez que não agregam a esta atividade os pilares fundamentais de autonomia e empoderamento, enfraquecendo deste modo a credibilidade dos usuários (clientes) nessa ferramenta de promoção à saúde ${ }^{(14)}$.

Conforme se percebeu nos discursos apresentados nos resultados, há elementos que se constituem como barreiras para a aplicação prática de atividades educativas, sendo a linguagem inteligível e os ambientes precários, os principais determinantes para o acadêmico. Estudo similar concorda com esses achados e acrescenta que as principais dificuldades para implementar ações educativas no cotidiano profissional, vão desde a desarticulação do trabalho em equipe, a carência de recursos de apoio ao processo educativo, as limitações de infraestrutura das unidades e a desvalorização da população ${ }^{(10)}$.

As dificuldades para implementar um processo educativo em saúde de modo mais eficaz, consistem também na fragilidade apresentada em algumas estruturas curriculares em cursos de graduação, que, uma vez baseadas num modelo de saúde biológico-tecnicista, não desenvolvem no estudante a consciência política ligada a essa estratégia, tornando-a assim mais uma obrigação meramente acadêmica, quando deveria ser principalmente um dever social.

Neste sentido, há necessidade de fortalecer as instituições de ensino e os seus formadores a criarem mecanismos criativos, participativos e crítico-reflexivos de tratar as práticas educativas em saúde, de modo que elas assumam um caráter transversal e ressonante na futura vida profissional dos acadêmicos, fazendo-os desenvolver nas comunidades os princípios de autonomia e empoderamento do sujeito.

\section{CONSIDERAÇÕES FINAIS}

A Educação em Saúde tem um importante destaque na formação de acadêmicos de enfermagem, e a partir da realização desta pesquisa reforça-se que é urgente a necessidade de destituir os modelos educativos tradicionais, baseados na passividade dos sujeitos e na relação de dominação do saber, para se apropriar de um modelo mais condizente com a diretriz do Sistema Único de Saúde voltada para a promoção da saúde, que busque sobremaneira permitir a relação dialógica, o protagonismo de todos os envolvidos no processo educativo e a valorização 
dos saberes empíricos da comunidade, na consolidação da formação dos estudantes de enfermagem.

Este estudo apresenta limitações pelo fato de ter sido desenvolvido em apenas uma IES, ressaltando-se a necessidade de que seja ampliado para outras instituições. Espera-se, contudo, que ele contribua para uma reflexão acerca das atividades educativas em saúde desenvolvidas pelos acadêmicos, bem como, oriente aos docentes, novas estratégias de reparar as arestas suscitadas pela pesquisa.

\section{REFERÊNCIAS}

1. Ministério da Saúde (BR). Glossário temático: gestão do trabalho e da educação na saúde. Brasília: Ministério da Saúde; 2008.

2. Colomé JS, Oliveira DLLC. Educação em Saúde: por quem e para quem? A visão de estudantes de graduação em enfermagem. Texto \& contexto enferm. [Inernet] 2012; 21(1) [acesso em 04 abr 2014]. Disponível: http://www.scielo.br/scielo.php?pid=S0104$07072012000100020 \&$ script=sci_arttext

3. Silva LD, Beck CLC, Dissen CM, Tavares JP, Budó MLD, Silva HS. O enfermeiro e a Educação em Saúde: um estudo bibliográfico. REUFSM [Internet] 2012; 2(2) [ acesso em 10 jun 2014]. Disponível: http://cascavel. ufsm.br/revistas/ojs-2.2.2/index.php/reufsm/article/ view/2676/3769

4. Pinafo E, Nunes EFPA, González AD, Garanhani ML. Relações entre concepções e práticas de Educação em Saúde na visão de uma equipe de saúde da família. Trab. educ. saúde [Internet] 2011; 9(2) [acesso em 10 abr 2014]. Disponível: http://www. scielo.br/scielo.php?script=sci_arttext\&pid=S198177462011000200003\&lng=pt\&nrm=iso

5. Sampaio SF, Kurcgant P. A participação acadêmica e sua influência na vida profissional segundo a percepção de enfermeiros. Rev. esc. enferm. USP [Internet] 2009; 43(1) [acesso em 10 abr 2014]. Disponível: http:// dx.doi.org/10.1590/S0080-62342009000100019.

6. Lefevre F, Lefevre AMC. O discurso do sujeito coletivo: um novo enfoque em pesquisa qualitativa (desdobramentos). Caxias do Sul: EDUSC; 2003.

7. Ministério da Saúde (BR). Conselho Nacional de Saúde. Diretrizes e normas regulamentadoras de pesquisa envolvendo seres humanos. Resolução n. 466, de 12 de dezembro de 2012. Brasília; 2012.

8. Ferreira VF, Rocha GOR, Lopes MMB, Santos MS, Miranda AS. Educação em Saúde e cidadania: revisão integrativa. Trab. educ. saúde [Internet] 2014; 12(2) [acesso em 21 nov 2014]. Disponível: http://dx.doi. org/10.1590/S1981-77462014000200009

9. Maciel MED. Educação em Saúde: conceitos e propósitos. Cogitare Enferm [Internet] 2009; 14(4) [acesso em 14 nov 2014]. Disponível: http://dx.doi. org/105380/ce.v14i4.16399.

10. Moutinho CB, Almeida ER, Leite MTS, Vieira MA. Dificuldades, desafios e superações sobre Educação em Saúde na visão de enfermeiros de saúde da família. Trab. educ. saúde [Internet] 2014; 12(2) [acesso em 21 nov 2014]. Disponível: http://dx.doi.org/10.1590/ S1981-77462014000200003

11. Figueiredo MFS, Rodrigues-Neto JF, Leite MTS. Modelos aplicados às atividades de Educação em Saúde. Rev Bras Enferm [Internet] 2010; 63(1) [acesso em 11 dez 2014]. Disponível: http://www.scielo.br/pdf/ reben/v63n1/v63n1a19.pdf

12. Carvalho AAS, Carvalho GS, Rodrigues VMCP. Valores na Educação em Saúde e a formação profissional. Trab. Educ. Saúde [Internet] 2012; 10(3) [acesso em 11 dez 2014]. Disponível em: http://dx.doi.org/S198177462012000300010

13. Almeida AH, Soares CB. Educação em Saúde: análise do ensino na graduação em enfermagem. Rev. LatinoAm. Enfermagem [Internet] 2011; 19(3) [acesso $11 \mathrm{dez}$ 2014]. Disponível: http://www.scielo.br/pdf/rlae/v19n3/ pt_22.pdf

14. Rodrigues CC, Ribeiro KSQS. Promoção da saúde: a concepção dos profissionais de uma unidade de saúde da família. Trab. educ. saúde [Internet] 2012; 10(2) [acesso em 14 nov 2014]. Disponível: http://dx.doi. org/S1981-77462012000200004. 